\title{
Heat-resistant properties of construction composites based on nanocarbon cement (nCMC)
}

\author{
Artemiy Cherkashin ${ }^{1}$, Yasmin Begich $^{1}$, Polina Sherstobitova ${ }^{1}$, Aleksandr Semencha ${ }^{1}$ and \\ Ivan Doroshin ${ }^{2, *}$ \\ ${ }^{1}$ Peter the Great St.Petersburg Polytechnic University, Polytechnicheskaya, 29, St. Petersburg, \\ 195251, Russia \\ ${ }^{2}$ Moscow State University of Civil Engineering, Yaroslavskoye shosse, 26, Moscow, 129337, Russia
}

\begin{abstract}
The article discusses the use of nano-modified cement. Comparative tests of samples made on the basis of the test material for compressive strength. A differential thermal analysis was performed.
\end{abstract}

\section{Introduction}

According to the Emergencies Ministry, only in the 4th quarter of 2018 in Russia, the number of fires is approaching 34 thousand, due to which thousands of people died. The greatest danger in a fire, in addition to poisoning by combustion products, is the collapse of the supporting structures of walls and floors made of concrete and reinforced concrete. The materials from which the building structures are made are exposed to high temperatures and undergo various changes. These changes are accompanied by characteristic signs, which are expressed in the form of transformation of physical, chemical and mechanical properties of substances and materials, in the development of deformation, destruction or complete destruction of parts of the building [1-5].

The main task of improving the safety of buildings and structures during operation is to improve the fire resistance and heat resistance of structures, for this it is important to use modern materials with enhanced heat-resistant properties [6-11]. Research of the behavior of high-strength concrete in case of fire and after temperature exposure showed that changing the structure of concrete by adding some components to its composition contributes to changing the properties of concrete [13].

In recent years, nanomaterials and composites based on them have become the most popular [14-18]. A construction composite based on nanocarbon cement grown on iron oxide in clinker was described in [19]. In previous research, a number of physicomechanical characteristics of the material, causes and conditions for the growth of carbon nanotubes were determined for this material. However, due attention is not paid to the heat-resistant properties of concrete and its connection with the structure change.

\footnotetext{
* Corresponding author: vskanhva@mail.ru
} 
In such a manner, the purpose of this research is to study the heat-resistant properties of building composites based on nanocarbon cement ( $\mathrm{nCMC}$ ):

1. Prepare samples in the laboratory;

2. Conduct differential thermal analysis of samples with $1 \%, 3 \%$ and $5 \% \mathrm{nCMC}$;

3. To test the samples of composites based on nanocarbon cement (nCMC) for compressive strength;

4. Analyze the collected data.

As a research object, a construction composite based on nanocarbon cement was chosen.

\section{Methods}

The cement used for this research has the following characteristic and compound: grade M500 D0, no additional mineral supplement, $\mathrm{C}_{3} \mathrm{~S}-60.42 \%, \mathrm{C}_{2} \mathrm{~S}-12.94 \%, \mathrm{C}_{3} \mathrm{~A}-5.72 \%$, $\mathrm{C}_{4} \mathrm{AF}-12.46 \%$. Placed in a reactor with an argon atmosphere the cement of clinker minerals is heated to a temperature of $650{ }^{\circ} \mathrm{C}$, the heating allows recovering hydrogen, and then argon got replaced by acetylene. As a result of catalytic decomposition of carbon in acetylene-hydrogen environment under atmospheric pressure, there can be noticed a growth of carbon nanotubes (CNTs) and nanofibers using carbon supersaturated iron catalyst (Fig. 1). The catalyst particles can stay at the top of the nanofibers or nanotubes (apical growth) or in ground (root growth). The number of nanostructures depends on the amount of iron catalyst. In this case, $1 \%$ by weight of the cement matrix [19].

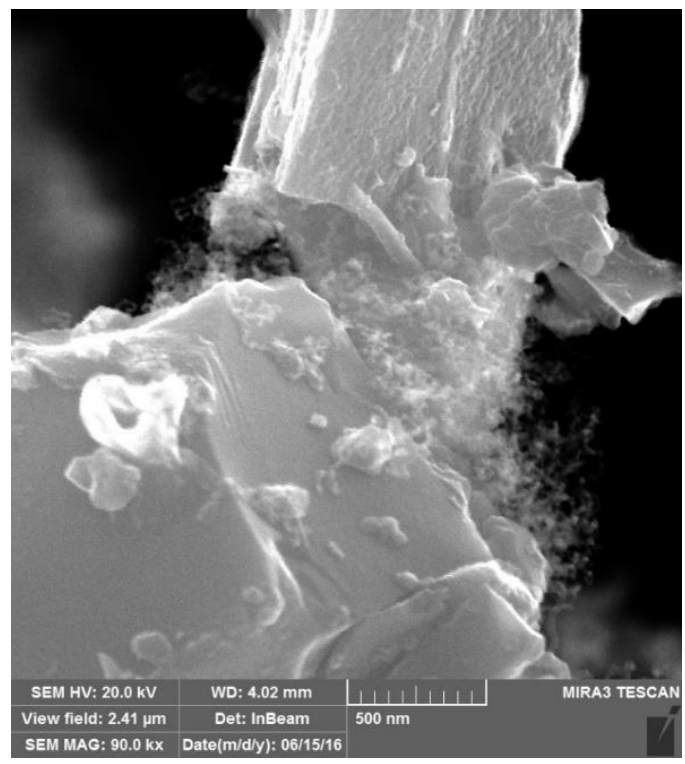

Fig. 1. Scanning Electron Microscopy image of the cement matrixes with CNTs.

For the manufacture of the control sample were used $500 \mathrm{~g}$ of cement, $1500 \mathrm{~g}$ of monofraction sand and $240 \mathrm{ml}$ of water. Pre-mixing of sand and cement was carried out in a spherical cup manually, then automatically in a runner mixer. The water/cement ratio for all mixtures is 0.48 .

To obtain comparable results, the above method for preparing a mortar mixture was also used in the preparation of samples with $1 \%, 3 \%$, and $5 \%$ nCMC. After achieving a uniform distribution of fiber in the cement-sand mixture, water was added. Tests for ultimate compressive strength were carried out at the age of 28 days. 
Further tests were carried out for a batch of similar samples, kept at a temperature of $485^{\circ} \mathrm{C}$ according to the method GOST 20910 for 4 hours and then cooled in a furnace to room temperature.

Also for samples subjected to thermal effects was carried out differential thermal analysis.

Differential thermal analysis (DTA) is based on the constant measurement and comparison of the temperatures of the test and control sample, taking into account the heat or cold applied. When the temperature in the sample changes, the process of enthalpy change (during melting, recrystallization, decomposition, oxidation, etc.) may occur with the release (absorption) of heat at different rates [20-23]. To record temperatures, a measuring cell is used, the circuit diagram of which is shown in Fig. 2.

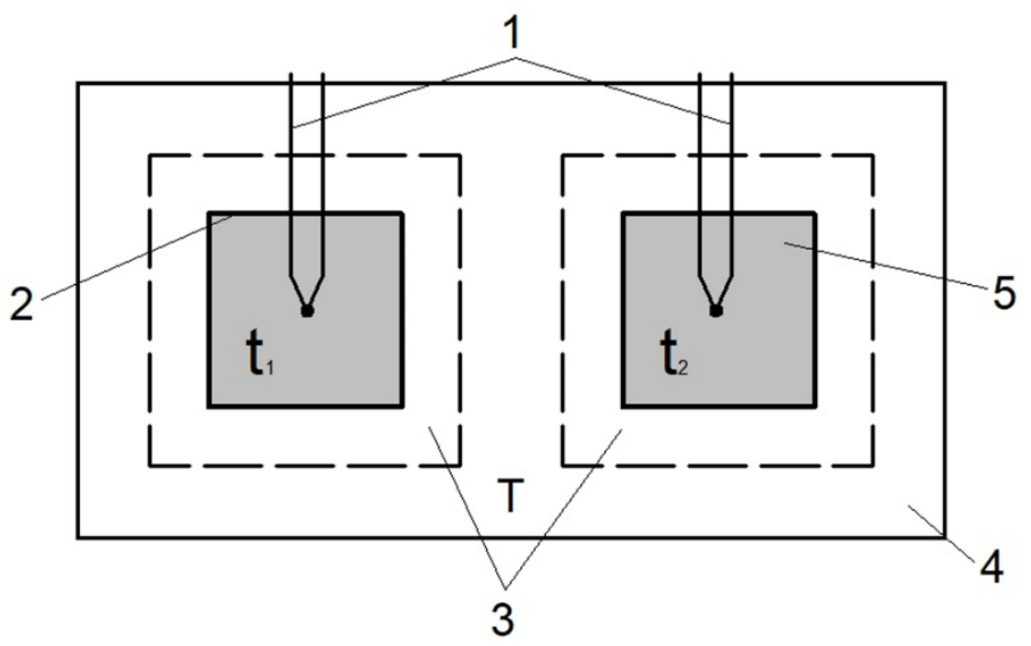

Fig. 2. DTA measuring cell. 1 - thermocouples to measure the temperature of the control and test sample; 2 - control sample; 3 - sample container; 4 - the general temperature environment; 5 - test sample.

The test and control specimens are located in symmetrically arranged containers relative to the whole construction of the measuring cell. Thermocouples (1 Fig. 2) simultaneously record the temperature change of the samples $\left(t_{1}, t_{2}\right)$ with time at summed temperature $(T)$. The effects associated with the transfer of heat within the cell are not taken into account, since their effect applies to both samples in the same way. At any time, the sample emits heat $\mathrm{dH} / \mathrm{dt}$, this heat is used to increase the temperature of the sample, or is dissipated in the environment (3, 4 Fig. 2).

\section{Experimental results and discussion}

Differential thermal analysis of samples from $1 \%, 3 \%$ and $5 \%$ of nCMC, and also without the content of nCMC showed that $\mathrm{Ca}(\mathrm{OH})_{2}$ decomposes in the area from $480^{\circ} \mathrm{C}$ to $550^{\circ} \mathrm{C}$, the cement stone becomes more porous, the corrosion of cement (Fig. 3). On the DTA curves, there is no significant correlation between the endothermic dips and the nCMC additives. Thus, there are no additional phases capable of hardening the concrete. Thus, the nature of the hardening of concrete $\mathrm{nCMC}$ is not thermodynamic. 


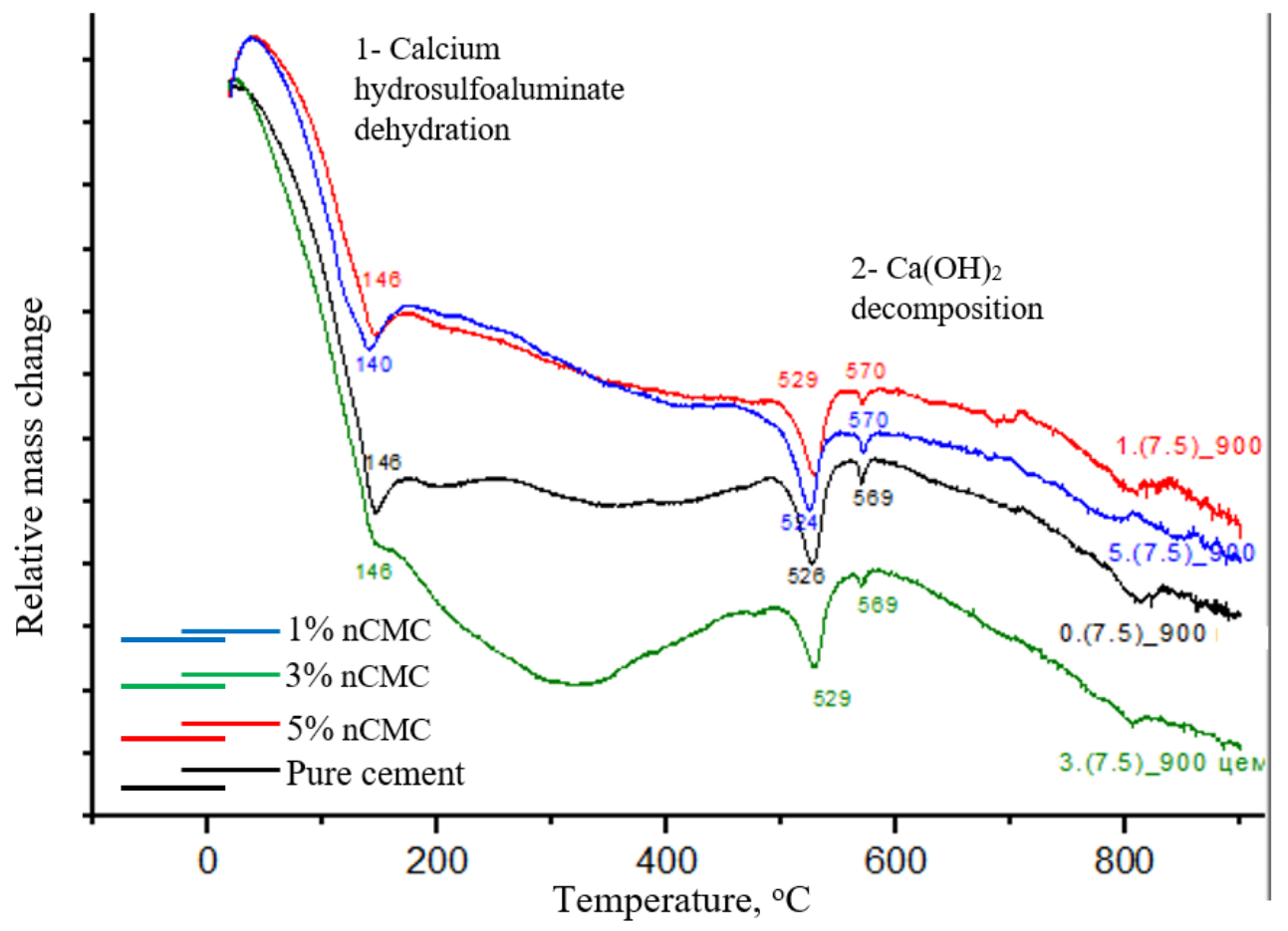

Fig. 3. Differential-thermal analysis of samples with different content of nCMC.

The compressive strength of a batch of control cubes of 50x50 mm with a change in the concentration of nCMC from 0 to $5 \%$ shows a tendency to increase in strength.

The results are presented in the Fig. 4.

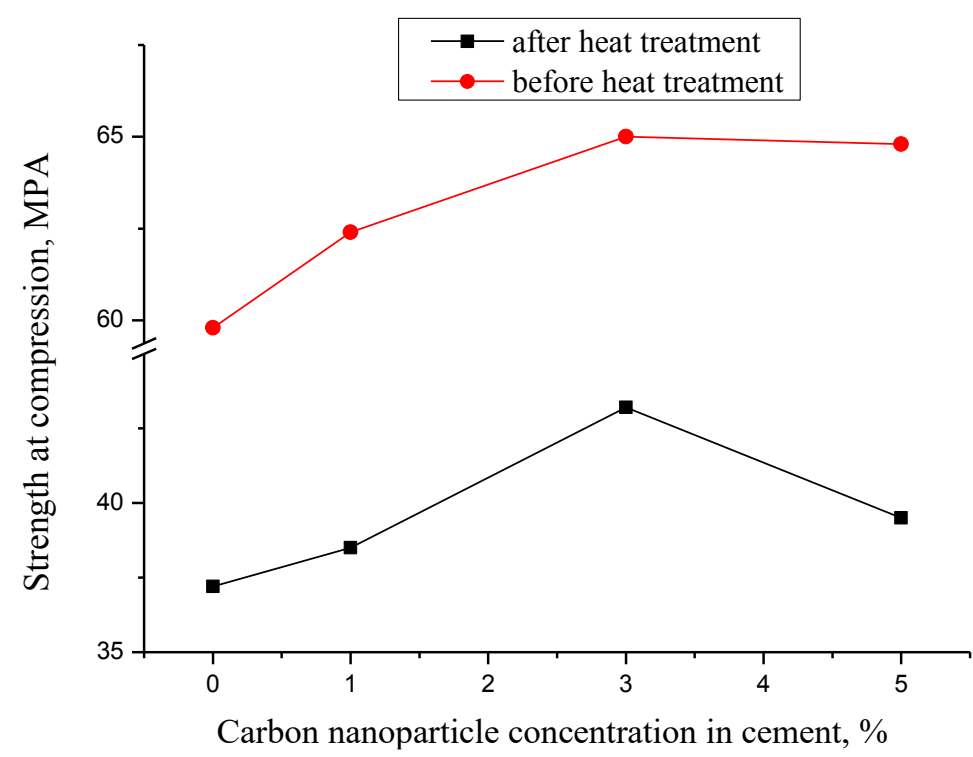

Fig. 4. The tensile strength of the samples of cement-sand cubes in compression with different content of the nCMC. 
A batch of similar samples maintained at a temperature of $485^{\circ} \mathrm{C}$ (Fig. 4), on average, reduced the strength of samples of all types. The highest strength values are shown by samples with a content of $3 \%$ nCMC.

\section{Conclusion}

The conducted research allows us to draw the following conclusions:

1. In the area from $480^{\circ} \mathrm{C}$ to $550^{\circ} \mathrm{C}, \mathrm{Ca}(\mathrm{OH})_{2}$ decomposes, the cement stone becomes more porous, the effect of corrosion of cement occurs. But despite this, the samples retain their strength due to the preservation of nanotube bonds, which have not collapsed under the influence of temperature, while the cement products have partially decomposed and no longer have sufficient resources to counteract the stresses arising in the samples.

2. The best results were shown by samples containing 3\% nCMC. This is explained by the fact that the presence of nanotubes, which can be seen in Fig. 1, indicates an increase in the strength characteristics of the material, since they perform a reinforcing role in the structure of concrete and discrete nanostructuring of cement systems [21].

\section{References}

1. M. Dham, T.S. Rushing, R. Helferich, T. Marth, S. Sengupta, R. Revur, C.A. Weiss, T.K. Cummins, Journal of the Transpor. Res. Board 2142, 18-24 (2010)

2. L.V. Dashko, G.V. Plotnikova, V.F. Golczewski, Bulletin of the east-siberian instit. of the MIA of Rus 4(71), 28-41 (2014)

3. T.V. Zagoruiko, Fire safety 20(10), 76-91 (2011)

4. A.A. Ledenev, T.V. Zagoruiko, V.T. Pertsev, A.A. Bondar, Probl. of secur. in the aftermath of emerg. 1, 42-44 (2012)

5. L.I. Dvorkin, O.L. Dvorkin, Coll. of sci. works of the Ukrainian State Academy of Railway Tran. 138, 32-39 (2013)

6. M.K. Pshembaev, Ya.N. Kovalev, L.I. Shevchuk, Science and technology 2, 87-94 (2016)

7. J.P. Little, H.A. Gray, D.W. Murray, D.J. Beard, H.S. Gill, Journal of arthroplasty 23(3), 43-57 (2008)

8. I. Harchenko, Fire Safety Bulletin 2(4), 17-32 (2000)

9. A.S. Pushenko, News of the Kazan St. Univer. of Arch. and Civil Engineering 1, 116$121(2008)$

10. V.S. Zyryanov, K.L. Kuznetsov, A.A. Shekov, Bulletin of the east-siberian instit. of the MIA of Rus. 3(74), 63-79 (2015)

11. G.V. Plotnikova, L.V. Dashko, V.Yu. Klyuchnikov, Bulletin of the east-siberian instit. of the MIA of Rus. 1(56), 75-83 (2011)

12. T.A. Hezhev, A.V. Zhurtov, A.S. Tsipinov, S.V. Klyuev, Mag. of Civil Engineering. 80(4), 181-194 (2018)

13. A.S. Pushenko, V.N. Azarov, Bulletin of the Volgograd St. Univer. of Arch. and Civil Engineering, Series: Build. and Arch. 7, 143-147 (2007)

14. S. V. Shirinkin, Business, Technology, Environment 10, 63-66 (2013)

15. B.W. Jo, J.S. Choi, S.W. Kang, Advanced Mat. Res. Trans Tech Publ. 148, 1717-1721 (2011) 
16. W.N. Al-Rifaie, O.M. Mahdi, W.K. Ahmed, Advanced Mat. Res. Trans Tech Publ. 795, 684-691 (2013)

17. B.W. Jo, S. Chakraborty, K.H. Kim, Y.S. Lee, Jour. of Nanomaterials 57, 62-77 (2014)

18. K. Sobolev, I. Flores, L.M. Torres-Martinez, P.L. Valdez, E. Zarazua, E.L. Cuellar. Nanotechnology in construction 3, 139-148 (2009)

19. A.V. Cherkashin, K.A. Pykhtin, Y.E. Begich, P.A. Sherstobitova, T.S. Koltsova, Mag. of Civil Engineering 4, 54-61 (2017)

20. L.V. Yankovsky, Online Journal of Science 4(13), 34-51 (2012)

21. M.O. Zhukov, Yu.N. Tolchkov, Z.A. Mikhaleva, Young Scientist 5, 16-20 (2012)

22. S.P. Lihtorovich, M.M. Nishchenko, I.E. Galstyan, Metal Physics and the Latest Technology 32(4), 475-486 (2010)

23. N.M. Ushakov, S.Y. Molchanov, Nanotechnology: Development, application-XXI century 7(4), 25-30 (2015) 